around the disc, especially to the nasal side and below. In distribution these dots are remarkably equidistant from each other, and are situated anteriorly to the largest retinal blood vessels, each being less than one-fifth of the diameter of a large vessel ; the outline of the disc is rather indistinct, the large veins full and somewhat tortuous. This appearance is most easily seen when the light is thrown somewhat obliquely on the part of the retina to be examined; the dots will then be seen to stand out well near the image of the border of the flame."

The first to misdescribe them is Frost, in the "Fundus Oculi." He describes them as occurring at the macula, and figures them in this position in four different plates. Weeks, in "Diseases of the Eye," 1911, says : "The macula lutea sometimes contains a number of minute spots or granules ('Gunn's' dots) which may be almost black, light-coloured, or glistening." Beard in Pyle's "System of Ophthalmic Practice," says : "In most eyes certain cells or groups of cells in the fovea are transparent, or free from pigment, permitting the red-orange tint of the chorio-capillaris to show as tiny dots. These have been named Gunn's dots, after the late Marcus Gunn, of London, who first described them." Oatman in his stereoscopic atlas, "Diagnostics of the Fundus Oculi," 1913, figures the dots at the macula, and describes it as "a dotted condition of the macula region, first described by Marcus Gunn and since known as Gunn's dots, or, from the family name of Gunn's first cases, 'Crick dots.' These terms are usually applied to small groups of light-coloured spots situated chiefly at the fovea." de Schweinitz, "Diseases of the Eye," 1916, says, in describing the foveal reflex: "This in turn is surrounded by a dark area (the dark spot of the macula), sometimes containing a number of brownish-black or light-coloured or even glistening granules, often called Gunn's dots, which have no pathologic significance."

Whether Gunn's dots have or have not any clinical importance, if considered worthy of notice in text-books, the original description should be followed.

\title{
Standards of Vision in Engine Drivers
}

Among the many problems, the consideration of which is held up by the war, is the fixing of standards of vision for engine drivers on the railways of this country. We believe the present railway regulations are in a chaotic condition. In some cases the tests are good, both as to form-sense and colour-sense, and the examinations are properly conducted. In other companies no standards seem to be fixed or the examinations are carried through in a most perfunctory fashion. We know the difficulties that have had to be faced in 
determining the tests for colour-vision in the mercantile marine, and these and other difficulties will have to be met in fixing the visual standards for railway service. The problem is not one for the ophthalmic surgeon alone, but there are certain points on which his aid is essential, and we know that it will be welcomed by the managing bodies of the great railway lines. Apart from the question of colour-vision, there is the need for settling what the minimum of form-sense is that can fit a man for driving an engine, and what kind of test is most suitable. To advise on this requires the combination of the oculist and the engine driver. In daytime there are various influences which affect the visibility of a signal, e.g., the nature of the background against which it shows, or the amount of shadow thrown by its surroundings at different times. Signals cannot always be placed so as to show up against a clear north sky. At night the luminosity and the colour of the signal become of an importance equal to the size. So far as we know, there has been no scientific eftort made to standardize any one of the factors nor to arrive at the minimum of form-sense which will enable a man to serve as an efficient and safe driver.

A further problem which will require very tactful handling is that of periodical re-examination. No ophthalmic surgeon will deny the need of this, both as regards form and colour; and yet even in the mercantile marine once a man has passed for his first colour-vision test he is subject to no further examination, although he is possibly more liable than men in other jobs to tobacco poisoning. We think that any ophthalmic surgeon who has an opportunity of considering the various problems involved, will be doing a service to the country if he can formulate some scheme as the basis of discussion.

\section{A Commission of Enquiry on Cinemas}

A Commission appointed by the National Council of Public Morals for Great and Greater Britain at the instance of certain cinematograph trade associations, has issued its Reportas an imposing volume containing nearly 300 pages.* As regards the well-known cinematograph eye-strain, the Commission recommended "a new copy of each film at every performance," but this was weakened by the addition of the words "or, at least, at frequent intervals." It was also suggested that children should sit at a distance from the screen not less than one and a half times its height, and that the front seats should be removed to at least twenty feet from the screen. The adequate illumination of the picture houses whilst the films are being shown, and other entertainment, as music and songs, were

*Williams and Norgate, London,1917, price 10s. 6d. net. 